\title{
COLETOR DE RESÍDUO BINÁRIO PARA 0 CAMPUS DA UNIVERSIDADE FEDERAL DE SANTA CATARINA
}

\section{Marina Koerich Préve (UFSC); Ana Veronica Pazmino, Dra. (UFSC)}

\section{INTRODUÇÃO}

Na Universidade Federal de Santa Catarina (UFSC), a comunidade universitária produz mensalmente cerca de 140,9 toneladas de resíduos convencionais (recicláveis, rejeitos e orgânicos).

Atualmente não há coleta seletiva na universidade, nem um sistema de coletores adequado que visa à separação dos diferentes resíduos descartados. Porém, com o novo Plano de Gerenciamento de Resíduos Sólidos (PGRS) que está sendo elaborado pela gestão dos resíduos sólidos da UFSC, o sistema de Coleta Seletiva Solidária (CSS) com coletores binários será implementado na universidade em 2017.

Este projeto de conclusão de curso de design visou desenvolver um coletor binário (rejeito e reciclável), capaz de permitir separar os resíduos descartados na área externa do campus universitário da UFSC.

\section{DESENVOLVIMENTO}

De modo a conhecer os usuários dos "coletores", foram realizadas entrevistas e pesquisa etnográfica com foco no trabalho que realizam os funcionários que realizam a coleta nos coletores.

Alguns requisitos como o material ser de concreto por ser durável e de baixo custo, a altura adequada para que o funcionário não tenha que fazer esforço e com tampa para evitar entrada de água de chuva, foram definidos.

Após a pesquisa com coletores de ambiente externo e a definição dos requisitos de projeto, foram geradas alternativas e após consulta com as responsáveis pela gestão de resíduos se chegou à solução que foi otimizada, detalhada e confeccionada em um modelo em escala 1:5 mostrado na Figura 1.

Priorizando a durabilidade e o custo final do produto, o material escolhido para o corpo do coletor foi o concreto armado. Para o material da tampa do coletor optou-se pelo aço inoxidável.

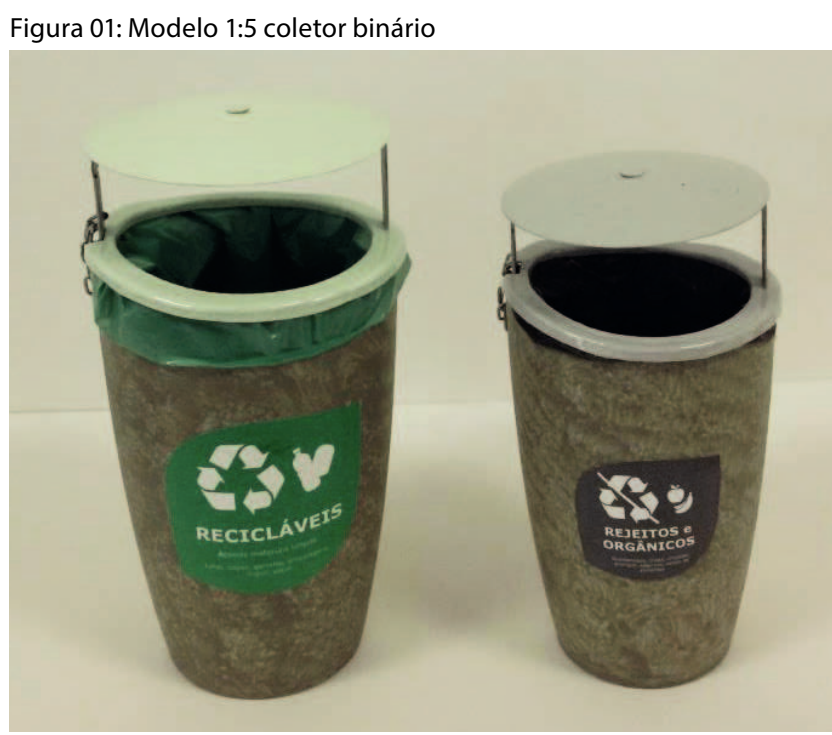

Fonte: Prevê (2017)

\section{CONCLUSÃO}

O coletor apresenta a robustez que a estética do concreto transmite, alia as formas orgânicas, sem linhas e pontas retas, com a estética do aço inoxidável que assegura maior leveza e modernidade. A aparência do aço inoxidável também transmite maior higiene, ponto importante no descarte e coleta de lixo.

A parte gráfica dos coletores traz aos usuários as informações necessárias para o correto descarte por meio de informações escritas, pelas cores e símbolos. As cores verdes e cinza facilitam a percepção da existência de diferentes resíduos de forma mais rápida e precisa.

O conjunto de coletores projetados poderá auxiliar na melhoria do posto de trabalho dos funcionários, contribuir no aproveitamento dos recursos descartados na universidade, trazer mais consciência e gerar um compromisso comunitário em relação aos resíduos descartados.

\section{REFERÊNCIAS}

BLEY JR, C. Lixo no Brasil e no Mundo. Seminário Nacional de Resíduos Sólidos e Limpeza Urbana, São Paulo, set. 2001. 
MOURTHÉ, Cláudia. Mobiliário urbano. Rio de Janeiro: 2ab Editora Itda, 1998.

SHIGUNOV NETO, Alexandre; CAMPOS, Lucila Maria de Souza; SHIGUNOV, Tatiana. Fundamentos da Gestão Ambiental. Rio de Janeiro: Ciência Moderna Ltda, 2009. 295p.

PREVÊ, Marina. Coletor de resíduo binário para o campus da Universidade Federal de Santa Catarina. Projeto de Conclusão de Curso de Design. Florianópolis. 2017. 